Journal of Aafiyah Health Research (JAHR)

P-ISSN : 2722-4929 \& E-ISSN : 2722-4945

Published by Master Program in Public health, Muslim University of Indonesia

Original Research

Open Access

\title{
Pengaruh Kepemimpinan, Organisasi, Tim Peningkatan Mutu Dan Efikasi Diri \\ Terhadap Penilaian Status Akreditasi Puskesmas Di Kota Makassar Tahun 2016-2019
}

\author{
Andri Anwar Zainuddin ${ }^{1}{ }^{*}$ Nurmiati Muchlis ${ }^{2}$, Reza Aril Ahri ${ }^{2}$ \\ ${ }^{1}$ Puskesmas Bira Kota Makassar \\ ${ }^{2}$ Program Pascasarjana Kesehatan Masyarakat, Universitas Muslim Indonesia \\ *Email:nurmiati.muchlis@umi.ac.id
}

\begin{abstract}
Background: Accreditation of Public Health Center (PHC) is one of the quality assessments or evaluations carried out by an accreditation body to improve quality and performance through continuous improvements to the quality management system and public health and clinical service delivery systems, as well as the application of risk management. There are several factors involved in health services at the PHC including leadership, organization, quality improvement team, and self-efficacy. This study aims to determine the influence of leadership, organization, and quality improvement teams with self-efficacy between accredited PHC which is Basic Intermediate and accredited PHC Prime - Plenary 2016-2019. Methods: This study used a quantitative approach with an observational design with a cross-sectional study design with a sampling technique based on a questionnaire distributed online. The sampling technique uses exhaustive sampling by taking all members of the population as a sample. The sample was 46 health centers with a total of 7 respondents each per PHC so that the total sample was 322 respondents. RThe analysis used in this study is Multiple Regression Analysis using the SPSS program. Results: The study of 322 respondents showed a significance value below 0.05 , which means that the variables of leadership, organization, Quality Improvement Team and SelfEfficacy have a significant effect on the assessment status of PHC accredited Basic - Intermediate with PHC accredited Prime - Plenary 2016-2019. Organization variable is the most significant variable based on statistical test results.
\end{abstract}

Keywords: Accreditation Status Assessment; Makassar City PHC, Leadership; Quality Improvement Team; Organization; Self-Efficacy 


\begin{abstract}
ABSTRAK
Latar Belakang: Akreditasi Puskesmas merupakan salah satu penilaian atau evaluasi mutu yang dilakukan oleh badan akreditasi untuk pembinaan peningkatan mutu dan kinerja melalui perbaikan yang berkesinambungan terhadap sistem manajemen mutu dan sistem penyelenggaraan kesehatan masyarakat dan pelayanan klinis, serta penerapan manajemen risiko. Ada beberapa faktor yang terlibat dalam pelayanan kesehatan di Puskesmas diantaranya faktor kepemimpinan, organisasi, tim peningkatan mutu, serta self-efficacy. Penelitian ini bertujuan untuk untuk mengetahui pengaruh kepemimpinan, organisasi, dan tim peningkatan mutu dengan self efficacy antara Puskesmas yang terakreditasi Dasar-Madya dengan Puskesmas yang terakreditasi Utama - Paripurna tahun 2016-2019. Metode: Penelitian ini menggunakan pendekatan kuantitatif dengan rancangan observasional dengan desain cross-sectional study dengan teknik pengambilan sampel berdasarkan kuesioner dan wawancara. Teknik pengambilan sampel menggunakan Exhaustive sampling dengan mengambil semua anggota populasi sebagai sampel. Sampel dalam penelitian ini adalah 46 Puskesmas dengan total responden masing-masing 7 orang per puskesmas sehingga total sampel adalah 322 responden. Analisis yang digunakan dalam penelitian ini adalah Analisis Regresi Berganda menggunakan program SPSS . Hasil penelitian dari 322 responden menunjukkan nilai signifikansi dibawah 0.05 artinya variabel Kepemimpinan, Organisasi, Tim Peningkatan Mutu dan Self-Efficacy berpengaruh signifikan terhadap terhadap status penilaian Puskesmas yang terakreditasi Dasar-Madya dengan Puskesmas yang terakreditasi Utama - Paripurna tahun 2016-2019. Dan variable organisasi merupakan variable yang paling bermakna berdasarkan hasil Uji Statistik.
\end{abstract}

Kata Kunci: Penilaian Status Akreditasi,; Puskesmas Kota Makassar; Kepemimpinan; Tim Peningkatan Mutu; Organisasi; Self-Efficacy

\section{LATAR BELAKANG}

Penguatan Pemberian layanan sangat penting untuk pencapaian tujuan pembangunan di bidang kesehatan. Penyediaan atau pemberian layanan merupakan output langsung dari input ke dalam sistem kesehatan, seperti tenaga kesehatan, pengadaan dan persediaan, dan pembiayaan. Peningkatan input harus mengarah pada peningkatan pemberian layanan dan peningkatan akses ke layanan kesehatan. Memastikan ketersediaan layanan kesehatan yang memenuhi dan menjaga kualitas standar pelayanan minimal adalah fungsi utama dari sistem kesehatan (1).

Fasilitas Pelayanan Kesehatan adalah suatu tempat yang digunakan untuk menyelenggarakan upaya pelayanan kesehatan, baik promotif, preventif, kuratif maupun rehabilitatif. Pusat Kesehatan Masyarakat (Puskesmas) merupakan fasilitas pelayanan kesehatan yang menyelenggarakan upaya kesehatan masyarakat dan upaya kesehatan perseorangan tingkat pertama yang dipimpin oleh seorang aparatur sipil negara dengan kualifikasi pendidikan kesehatan strata satu atau diploma empat untuk daerah perkotaan dan minimal diploma tiga untuk daerah terpencil dan sangat terpencil serta memiliki kemampuan manajemen dibidang kesehatan masyarakat (2).

Puskesmas merupakan ujung tombak pelayanan bagi masyarakat karena cukup 
efektif membantu masyarakat dalam memberikan pertolongan pertama dengan standar pelayanan kesehatan. Pelayanan kesehatan yang dikenal murah seharusnya menjadikan puskesmas sebagai tempat pelayanan kesehatan utama bagi masyarakat, namun pada kenyataannya banyak masyarakat yang lebih memilih pelayanan kesehatan pada dokter praktik swasta atau petugas kesehatan praktik lainnya.

Kondisi ini di dasari oleh persepsi awal yang negatif dari masyarakat terhadap pelayanan puskesmas, misalnya anggapan bahwa mutu pelayanan yang terkesan seadanya, artinya puskesmas tidak cukup memadai, baik dilihat dari sarana dan prasarananya maupun dari tenaga medis atau anggaran yang digunakan untuk menunjang kegiatannya sehari-hari. Sehingga banyak pelayanan yang diberikan kepada masyarakat tidak sesuai dengan Standar Operasional Prosedur (SOP) yang telah ditetapkan (3).

Untuk menjamin perbaikan mutu, peningkatan kinerja dan penerapan manajemen risiko dilaksanakan secara berkesinambungan di fasilitas pelayanan kesehatan primer dan rujukan, maka perlu dilakukan penilaian oleh pihak eksternal dengan menggunakan standar yang diterapkan melalui mekanisme akreditasi (4).

Akreditasi merupakan salah satu penilaian atau evaluasi mutu dan kelayakan institusi yang dilakukan oleh organisasi atau badan akreditasi. Akreditasi merupakan suatu proses dan hasil. Sebagai proses, akreditasi merupakan suatu upaya untuk menilai dan menentukan status mutu berdasarkan standar mutu yang telah ditetapkan. Sebagai hasil akreditasi merupakan status mutu yang diumumkan kepada masyarakat. Pengukuran kualitas pelayanan dengan metode akreditasi telah diterapkan sebagai salah satu alat ukur untuk memastikan kualitas layanan dan penggunaan sumber daya yang efisien dan efektif (5).

Peningkatan mutu pelayanan sebagai suatu konsep menurut Baldrige memiliki dimensi, antara lain: kepemimpinan, perencanaan strategis, fokus terhadap pasien yang dilayani, pengukuran, analisis dan pengetahuan manajemen, fokus pada sumber daya manusia, program manajemen, dan hasil yang diperoleh (6). Konsep mutu yang dikembangkan oleh Kaplan lebih fokus pada pelayanan kesehatan yang membagi mutu dalam lima dimensi, yaitu: mikrosistem, organisasi (makrosistem), level lingkungan, tim peningkatan mutu, dukungan dan kapasitas peningkatan mutu (7).

Penjaminan mutu merupakan proses peninjauan yang terencana dan sistematis untuk memastikan kesesuaian dari aktivitas semua unsur manajemen dalam organisasi mencapai standar, untuk mencapai hal tersebut maka dibutuhkan efikasi diri (self efficacy) atau sikap keyakinan seseorang terhadap kemampuan dirinya dalam melaksanakan tugas untuk mencapai suatu keberhasilan (8)

Penilaian puskesmas dilakukan selama 3 hari dengan menggunakan instrumen akreditasi puskesmas yang telah disusun dan ditetapkan Kementerian Kesehatan Repulik Indonesia yang terdiri dari 9 bab, 42 standar, 168 kriteria dan 776 elemen penilaian. Penetapan Status Akreditasi untuk Puskesmas terdiri dari : (1) Tidak terakreditasi; (2) Akreditasi Dasar; (3) Akreditasi Madya; (4) Akreditasi Utama, atau (5) Akreditasi Paripurna $(9,10)$. 
Berdasarkan data dari Dinas Kesehatan Kota Makassar Tahun 2019, jumlah puskesmas yang ada di Kota Makassar sebanyak 47 puskesmas dan yang telah diakreditasi sebanyak 46 puskesmas dan yang belum diakreditasi 1 puskesmas. Puskesmas dengan status akreditasi Paripurna ada 2 Puskesmas, 21 puskesmas terakreditasi utama, 16 puskesmas terakreditasi madya dan 7 puskesmas terakreditasi Dasar.

Tujuan diberlakukannya akreditasi puskesmas adalah untuk meningkatkan mutu pelayanan kesehatan pada puskesmas, sehingga dari mutu pelayanan kesehatan yang ditingkatkan dapat memberikan kepuasan bagi pasien atau masyarakat yang menerima pelayanan kesehatan tersebut (11). Akan tetapi laporan hasil survey kepuasan masyarakat terhadap pelayanan Puskesmas dan RSUD Kota Makassar, menyatakan bahwa keluhan di masyarakat tetap ada meskipun nilai akreditasi puskesmas yang diperoleh utama ataupun paripurna (12).

Penelitian yang dilakukan Wissam HajAli dkk tahun 2014 di Lebanon yang bertujuan untuk mengeksplorasi dampak sistem akreditasi nasional Lebanon terhadap kepuasan pasien dengan metode studi crosssectional explanatory terhadap enam rumah sakit di Lebanon (13). Kolaborasi lintas negara dalam mengevaluasi dan mentransformasikan upaya reformasi pelayanan kesehatan primer di Kanada kemungkinan akan menghasilkan pelajaran penting bagi pengalaman di Amerika Serikat (14).

Penelitian yang dilakukan oleh Heuer (15) yang hubungan antara dua indikator kualitas, akreditasi dan kepuasan pasien terhadap 41 rumah sakit yang telah mendapat nilai akreditasi dari Commission on Accreditation of Healthcare Organizations menunjukkan tidak ada hubungan signifikan antara skor akreditasi yang mewakili kualitas pelayanan dengan penilaian kepuasan pasien yang merupakan indikator kualitas layanan.

Hasil penelitian di Puskesmas X di Kota Surabaya oleh Nurul Hidayatul tahun 2018 menunjukkan bahwa pelaksanaan upaya keselamatan pasien telah disesuaikan dengan standar penilaian akreditasi Puskesmas akan tetapi masih terdapat hambatan dan kekurangan dalam pemenuhan standar upaya keselamatan pasien sehingga perlu optimalisasi penerapan upaya tersebut dari seluruh pihak yang terlibat, dalam hal ini peran tim peningkatan mutu sangat diperlukan untuk peningkatan mutu pelayanan Puskesmas (16).

Dalam penelitian oleh Eko Susanto tahun 2018 menyatakan bahwa efikasi diri berpengaruh langsung terhadap kinerja Pegawai. Hal ini menunjukan bahwa keyakinan atas kemampuan yang dimiliki oleh pegwai puskesmas dapat memberikan dampak yang positif terhadap kinerja pegawai puskesmas (17)

Peneliti tertarik untuk melakukan kajian studi komparatif untuk melihat pengaruh kepemimpinan, organisasi dan tim peningkatan mutu dengan self efficacy terhadap akreditasi Puskesmas karena belum ada penelitian yang menghubungkan status akreditasi dengan faktor kepemimpinan, organisasi, tim peningkatan mutu, dan yang terlibat dalam pelayanan kesehatan di Puskesmas Kota Makassar,

\section{METODE}

Penelitian ini menggunakan pendekatan kuantitatif dengan rancangan observasional 
dengan desain cross-sectional study, yaitu suatu penelitian yang bertujuan untuk melihat suatu hubungan antara variabelvariabel independent dan variabel dependen,. Lokasi Penelitian di 46 Puskesmas terakreditasi di Kota Makassar

Populasi dan sampel dalam penelitian ini adalah seluruh anggota tim yang terlibat dalam akreditasi puskesmas di Kota Makassar yang sudah terakreditasi berjumlah 46 Puskesmas terdiri dari Kepala Puskesmas, Kepala Tata Usaha (KTU), Penanggung Jawab UKM dan Keperawatan Kesehatan Masyarakat, Penanggung jawab UKP, Kefarmasian dan Laboratorium, dan Penanggung Jawab Jaringan Jejaring Puskesmas, Penanggungjawab bangunan, sarana dan peralatan puskesmas, dan Penanggung Jawab Mutu. Teknik pengambilan sampel dalam penelitian ini adalah Exhaustive sampling (total sampling) yaitu teknik memilih sampel dengan melakukan survei kepada seluruh populasi yang ada atau mengambil semua anggota populasi sebagai sampel (18). Sampel yang diambil dari penelitian ini adalah 46 Puskesmas dengan total responden masingmasing 7 orang per puskesmas sehingga total sampel adalah 322 responden.

Teknik Pengumpulan data diawali dengan pemberian informant concent kemudian dilakukan Observasi yaitu proses melakukan pengamatan langsung pada Puskesmas yang ada di Kota Makassar yang sudah terakreditasi dengan menggunakan kuesioner yang disebarkan kepada responden melalui google form untuk di jawab sesuai dengan pendapatnya tentang variabel kepemimpinan, organisasi dan tim peningkatan mutu serta self efficacy terkait akreditasi puskesmas.

\section{HASIL}

Penelitian ini dilaksanakan di 46 Puskesmas di Kota Makassar selama 30 hari, mulai tanggal 20 Juli sampai dengan 20 Agustus 2020, Penelitian ini menggunakan pendekatan kuantitatif dengan rancangan observasional dengan desain cross-sectional study, yaitu suatu penelitian yang bertujuan untuk melihat hubungan suatu variabel dengan variabel lain. Data diolah dan dianalisis disesuaikan dengan tujuan penelitian. Hasil analisis data disajikan dalam bentuk tabel dilengkapi dengan penjelasan sebagai berikut:

\section{Analisis Univariat}

Analisis univariat dilakukan untuk mendapatkan gambaran deskriptif dari tiaptiap variabel yang diteliti.

Tabel 1. Distribusi Berdasarkan Karakteristik Responden 46 Puskesmas di Kota Makassar Tahun 2016-2019

Variabel

\section{Kelompok Umur}

26-29 tahun

30-33 tahun

34-37 tahun

38-41 tahun
Total

n

2

30

67

66
\%

0.6

9.3

20.8

20.5 


\begin{tabular}{|c|c|c|}
\hline $42-45$ tahun & 41 & 12.7 \\
\hline 46-49 tahun & 35 & 10.9 \\
\hline $50-53$ tahun & 28 & 8.7 \\
\hline 54-57 tahun & 36 & 11.2 \\
\hline$>=59$ tahun & 17 & 5.3 \\
\hline Total & 322 & 100.0 \\
\hline \multicolumn{3}{|l|}{ Jenis Kelamin } \\
\hline laki-laki & 51 & 15.8 \\
\hline Perempuan & 271 & 84.2 \\
\hline Total & 322 & 100.0 \\
\hline \multicolumn{3}{|l|}{ Jabatan dalam Organisasi } \\
\hline kepala puskesmas & 46 & 14,3 \\
\hline KTU & 46 & 14,3 \\
\hline PJ UKM \& keperawatan & 46 & 14,3 \\
\hline PJ UKP, kefarmasian dan Lab & 46 & 14,3 \\
\hline Ketua Tim Mutu & 46 & 14,3 \\
\hline PJ Jaringan dan Jejaring & 46 & 14,3 \\
\hline PJ Bangunan sarana dan peralatan & 46 & 14,3 \\
\hline Total & 322 & 100 \\
\hline \multicolumn{3}{|l|}{ Lama Bekerja } \\
\hline $1-4$ tahun & 20 & 6,2 \\
\hline $5-8$ tahun & 20 & 6,2 \\
\hline 9-12 tahun & 99 & 30,7 \\
\hline 13-16 tahun & 68 & 21,1 \\
\hline 17-20 tahun & 27 & 8,4 \\
\hline 21-24 tahun & 19 & 5,9 \\
\hline 25-28 tahun & 30 & 9,3 \\
\hline 29-32 tahun & 24 & 7,5 \\
\hline$>=33$ tahun & 15 & 4,7 \\
\hline Total & 322 & 100 \\
\hline \multicolumn{3}{|l|}{ Status Kepegawaian } \\
\hline $\mathrm{ASN}$ & 319 & 99,1 \\
\hline Non ASN & 3 & 0,9 \\
\hline Total & 322 & 100 \\
\hline \multicolumn{3}{|l|}{ Pendidikan Terakhir } \\
\hline S1 & 202 & 62,7 \\
\hline S2 & 67 & 20,8 \\
\hline D3 & 41 & 12,7 \\
\hline Lainnya & 11 & 3,4 \\
\hline $\mathrm{S} 3$ & 1 & 0,3 \\
\hline Total & 322 & 100 \\
\hline
\end{tabular}




\begin{tabular}{lcc} 
Wilayah Kerja Puskesmas & & \\
Perkotaan & 308 & 95,7 \\
Kepulauan & 14 & 4,3 \\
Total & 322 & 100 \\
\hline Pelayanan Puskesmas & & \\
Rawat inap & 84 & 26,1 \\
Non rawat inap & 238 & 73,9 \\
Total & 322 & 100 \\
\hline
\end{tabular}

Sumber: Data Primer, 2020

\section{Karakteristik sampel}

\section{Kelompok Umur}

Umur sampel adalah lamanya hidup seorang sampel sejak dilahirkan sampai ulang tahun terakhir yang dinyatakan dalam tahun kalender. Kelompok umur dapat dilihat pada tabel 1 menunjukkan bahwa dari 322 responden penelitian di 46 Puskesmas terakreditasi di Kota Makassar dengan umur tertinggi lebih dari atau sama dengan 59 tahun sebanyak 17 orang dengan presentase $5,3 \%$. Sedangkan dari 322 responden penelitian, kelompok umur terendah yaitu 26-29 tahun sebanyak 2 orang dengan presentase $0,6 \%$.

\section{Jenis Kelamin}

Berdasarkan hasil survey/hasil olah data ditemukan bahwa jenis kelamin responden terdiri atas 271 perempuan dan 51 orang laki-laki. Karakteristik responden berdasarkan jenis kelamin diuraikan dalam tabel 1 menunjukkan bahwa dari 322 responden penelitian di 46 Puskesmas terakreditasi di Kota Makassar dengan jumlah responden jenis kelamin laki-laki sebanyak 51 orang dengan presentase sebesar $15,8 \%$. Sedangkan jumlah responden perempuan sebanyak 271 orang dengan presentase sebesar $84,2 \%$.

\section{Jabatan}

Jabatan responden adalah pakerjaan/tugas responden dalam struktur organisasi puskesmas. Karakteristik responden berdasarkan jabatan diuraikan dalam tabel 1 menunjukkan bahwa dari 322 responden penelitian di 46 Puskesmas terakreditasi di Kota Makassar dengan jabatan kepala puskesmas, KTU, PJ UKP, Kefarmasian dan laboratorium \& PJ UKM dan keperawatan kesehatan masyarakat, ketua tim mutu, PJ jaringan dan jejaring puskesmas, PJ bangunan, sarana dan peralatan masingmasing berjumlah 46 orang dengan presentase masing-masing $14,3 \%$

\section{Bekerja}

Lama bekerja adalah kurun waktu atau lamanya responden mulai bekerja dalam lingkup Dinas Kesehatan/ Puskesmas hingga jangka waktu tertentu. Karakteristik responden berdasarkan lama bekerja diuraikan dalam tabel 1 menunjukkan bahwa dari 322 responden penelitian di 46 Puskesmas terakreditasi di Kota Makassar dengan masa kerja paling lama lebih dari atau sama dengan 33 tahun sebanyak 15 
orang dengan presentase sebesar 4,7 \%. Sedangkan masa kerja singkat yaitu 1-4 tahun sebanyak 20 orang dengan presentase sebesar $6,2 \%$.

\section{Status kepegawaian}

Status kepegawaian adalah keadaan yang membedakan pegawai yang satu dengan pegawai yang lain dalam hal ini dalam lingkup pemerintahan terdiri atas ASN dan Non ASN/Kontrak. Karakteristik responden berdasarkan status kepegawaian diuraikan dalam tabel 1 menunjukkan bahwa dari 322 responden penelitian di 46 Puskesmas terakreditasi di Kota Makassar, jumlah responden dengan status kepegawaian PNS sebanyak 319 orang dengan presentase sebesar 99,1\% sedangkan jumlah responden dengan status kepegawaian non PNS sebanyak 3 orang dengan presentase sebesar $0,9 \%$.

\section{Pendidikan Terakhir}

Pendidikan terakhir adalah jenjang pendidikan terakhir secara formal yang pernah diikuti oleh responden penelitian. Hasil penelitian terhadap pengelompokan pendidikan terakhir dapat dilihat pada tabel 1 menunjukkan bahwa dari 322 responden penelitian di 46 Puskesmas terakreditasi di Kota Makassar, jumlah responden dengan pendidikan terakhir D3 sebanyak 41 orang dengan presentase 12,7\%, S1 sebanyak 202 orang dengan presentase $62,7 \%$, S2 sebanyak 67 orang dengan presentase $20,8 \%$, S3 sebanyak 1 orang dengan presentase $0,3 \%$, dan lainnya sebanyak 11 orang dengan presentase $3,4 \%$.

\section{Wilayah Kerja Puskesmas}

Wilayah Kerja Puskesmas adalah wilayah kerja meliputi satu kecamatan atau sebagian kecamatan berdasarkan faktor kepadatan penduduk,luas daerah,keadaan geografik dan keadaan infrastruktur lainnya. Wilayah kerja Puskesmas dalam lingkup Dinas Kesehatan Kota Makassar terdiri dari puskesmas wilayah perkotaan dan kepulauan. Tabel 1 menunjukkan bahwa dari sampel berjumlah 46 Puskesmas terakreditasi di Kota Makassar, dari 322 responden, jumlah responden dengan wilayah kerja puskesmas perkotaan adalah 308 orang dengan presentase sebesar $95,7 \%$ sedangkan, jumlah responden dengan wilayah kerja puskesmas kepulauan adalah 14 orang dengan presentase sebesar $4,3 \%$

\section{Kemampuan Pelayanan Puskesmas}

Kemampuan pelayanan puskesmas adalah kemampuan puskesmas untuk memberikan penyelenggaraan pelayanan kesehatan yang terdiri dari pelayanan non rawat inap dan pelayanan rawat inap. Karakteristik berdasarkan kemampuan pelayanan puskesmas diuraikan dalam tabel 1 menunjukkan bahwa dari sampel berjumlah 46 Puskesmas terakreditasi di Kota Makassar, dari 322 responden, jumlah responden dengan pelayanan rawat inap sebesar 84 orang dengan presentase $26,1 \%$ sedangkan jumlah responden dengan pelayanan non rawat inap sebesar 238 orang dengan presentase $73,9 \%$

\section{Kepemimpinan}

Kepemimpinan adalah kemampuan untuk mempengaruhi orang lain untuk melakukan suatu tujuan bersama dalam rangka peningkatan mutu dan terlibat dalam mendukung dan memfasilitasi upaya peningkatan tersebut. Karakteristik 
berdasarkan faktor kepemimpinan diraikan dalam tabel 1 menunjukkan bahwa dari 322 responden penelitian di 46 Puskesmas terakreditasi di Kota Makassar, untuk faktor kepemimpinan yang menjawab cukup berjumlah 244 orang dengan presentase $75,8 \%$ sedangkan yang menjawab kurang berjumlah 78 orang dengan presentase $24,2 \%$

\section{Organisasi}

Organisasi puskesmas merupakan sistem kerjasama untuk mencapai tujuan bersama dari unit fungsional dan layanan yang bekerja secara profesional di Puskesmas yang terdiri atas kepala puskesmas, Kepala Tata Usaha, serta Peanggungjawab. Karakteristik berdasarkan Organisasi Puskesmas diuraikan dalam table 1 menunjukkan bahwa dari 322 responden penelitian di 46 Puskesmas terakreditasi di Kota Makassar, untuk faktor organisasi yang menjawab cukup berjumlah 235 orang dengan presentase $73 \%$ sedangkan yang menjawab kurang berjumlah 87 orang dengan presentase $27 \%$.

\section{Tim Peningkatan Mutu}

Tim peningkatan mutu merupakan sekelompok orang dalam siklus atau proses yang terstruktur untuk memperbaiki sistem dan proses kerja dalam struktur organisasi puskesmas. Karakteristik berdasarkan tim peningkatan mutu diuraikan dalam table 1 menunjukkan bahwa dari 322 responden penelitian di 46 Puskesmas terakreditasi di Kota Makassar, untuk faktor tim peningkatan mutu, yang menjawab cukup berjumlah 240 orang dengan presentase 74,5 $\%$ sedangkan yang menjawab kurang berjumlah 82 orang dengan presentase $25,5 \%$.

\section{Status Akreditasi}

Status Akreditasi Puskesmas adalah pengakuan yang diberikan oleh lembaga independen pengelenggara akreditasi yang ditetapkan oleh menteri kesehatan setelah memenuhi standar akreditasi yang dibuktikan dengan sertifikat akreditasi yang terdiri atas tidak terakreditasi, terakreditasi dasar, madya, utama, atau paripurna. Tabel 1 menunjukkan bahwa dari 322 responden penelitian di 46 Puskesmas terakreditasi di Kota Makassar, status akreditasi puskesmas dasar-madya sebanyak 23 Puskesmas dengan responden berjumlah 161 orang dengan presentase $50 \%$ sedangkan status akreditasi utama-paripurna sebanyak 23 Puskesmas dengan responden berjumlah 161 orang dengan presentase $50 \%$.

\section{Self Efficacy}

Self Efficacy adalah penilaian diri, apakah dapat melakukan tindakan yang baik atau buruk, tepat atau salah, bisa atau tidak bisa mengerjakan sesuatu sesuai yang dipersyaratkan. Karakteristik berdasarkan self efficacy diuraikan dalam tabel 1 menunjukkan bahwa dari 322 responden penelitian di 46 Puskesmas terakreditasi di Kota Makassar, untuk Self-Efficacy, yang menjawab cukup berjumlah 228 orang dengan presentase $70,8 \%$ sedangkan yang menjawab kurang berjumlah 94 orang dengan presentase $29,2 \%$.

\section{Analisis Bivariat}

Analisis bivariat dimaksudkan untuk mengetahui pengaruh variabel independen terhadap variabel dependen. Analisis Bivariat dapat dilihat pada tabel berikut ini : 
Tabel 2. Pengaruh Faktor Kepemimpinan, Organisasi, Tim Peningkatan Mutu, dan Self Efficacy antara Puskesmas yang terakreditasi Dasar-Madya dengan Puskesmas yang terakreditasi Utama-Paripurna tahun 2016-2019

\begin{tabular}{|c|c|c|c|c|c|c|c|c|}
\hline \multirow[t]{3}{*}{ Variabel } & \multicolumn{4}{|c|}{ Status Akreditasi } & \multirow[t]{3}{*}{ Jumlah } & \multirow[t]{3}{*}{$\mathbf{X}^{2}$} & \multirow[t]{3}{*}{$\mathbf{p}$} & \multirow[t]{3}{*}{$\varphi$} \\
\hline & \multicolumn{2}{|c|}{ Dasar-Madya } & \multicolumn{2}{|c|}{$\begin{array}{c}\text { Utama- } \\
\text { Paripurna }\end{array}$} & & & & \\
\hline & $\mathbf{n}$ & $\%$ & $\mathbf{n}$ & $\%$ & & & & \\
\hline \multicolumn{9}{|c|}{ kepemimpinan } \\
\hline Kurang & 54 & 69.2 & 24 & 30.8 & 78 & & & \\
\hline Cukup & 107 & 43.9 & 137 & 56,1 & 244 & 15,227 & 0 & 0,217 \\
\hline Jumlah & 161 & 50 & 161 & 50 & 322 & & & \\
\hline \multicolumn{9}{|l|}{ Organisasi } \\
\hline Kurang & 53 & 60.9 & 34 & 39.1 & 87 & & & \\
\hline Cukup & 108 & 46.0 & 127 & 54 & 235 & 5,686 & 0,017 & 0,13 \\
\hline Jumlah & 161 & 50 & 161 & 50 & 322 & & & \\
\hline \multicolumn{9}{|c|}{ Tim Peningkatan Mutu } \\
\hline Kurang & 55 & 67.1 & 27 & 32.9 & 82 & & & \\
\hline Cukup & 106 & 44.2 & 134 & 55.8 & 240 & 12.828 & 0 & 0,2 \\
\hline Jumlah & 161 & 50 & 161 & 50 & 322 & & & \\
\hline \multicolumn{9}{|l|}{ Self Efficacy } \\
\hline Kurang & 58 & 61.7 & 36 & 38.3 & 94 & & & \\
\hline Cukup & 103 & 45.2 & 125 & 54.8 & 228 & 7.272 & 0,007 & 0,15 \\
\hline Jumlah & 161 & 50 & 161 & 50 & 322 & & & \\
\hline
\end{tabular}

Sumber : Data Primer, 2020

Pengaruh Faktor Kepemimpinan dengan self-efficacy antara Puskesmas yang terakreditasi Dasar-Madya dengan Puskesmas yang terakreditasi UtamaParipurna tahun 2016-2019

Pengaruh faktor kepemimpinan dengan self-efficacy antara puskesmas yang terakreditasi dasar-madya dengan puskesmas yang terakreditasi utama-paripurna tahun 2016-2019 pada Tabel 2 menunjukkan bahwa dari 244 responden dengan faktor kepemimpinan yang Cukup terdapat 137 responden dengan penilaian akreditasi utama-paripurna atau sebesar $56,1 \%$ dan dari 78 responden dengan faktor kepemimpinan yang Kurang, sebanyak 24 responden dengan penilaian status akreditasi utamaparipurna atau sebesar $30.8 \%$.

Hasil uji chi square diperoleh nilai

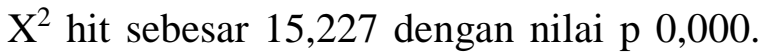
Karena nilai $\mathrm{X}^{2}$ hit > dari 3,841 dan nilai $\mathrm{p}<$ 0,05 , ini berarti bahwa ada pengaruh antara faktor kepemimpinan dengan self efficacy terhadap penilaian status akreditasi Puskesmas.

Hasil uji kekuatan hubungan dengan uji Phi Cramer diperoleh sebesar $\varphi$ 0,217. Karena nilai $\varphi$ berada pada rentang nilai 0,01-0,25 ini berarti pengaruh sangat lemah 
dan memberikan kontribusi $21,7 \%$ terhadap penilaian status akreditasi Puskesmas

Pengaruh faktor organisasi dengan Selfefficacy antara Puskesmas yang terakreditasi Dasar-Madya dengan Puskesmas yang terakreditasi UtamaParipurna tahun 2016-2019

Pengaruh faktor organisasi dengan self-efficacy antara puskesmas yang terakreditasi dasar-madya dengan puskesmas yang terakreditasi utama-paripurna tahun 2016-2019 pada Tabel 2 menunjukkan bahwa dari 87 responden dengan faktor organisasi yang Kurang terdapat 34 responden dengan status penilaian akreditasi utama-paripurna sebesar $39.1 \%$ dan dari 235 responden dengan faktor organisasi yang Cukup terdapat 127 responden dengan status penilaian akreditasi utama-paripurna sebesar $54,0 \%$.

Hasil uji chi square diperoleh nilai $\mathrm{X}^{2}$ hit sebesar 5,686 dengan nilai $\mathrm{p}$ 0,00. Karena nilai $\mathrm{X}^{2}$ hit > dari 3,841 dan nilai $\mathrm{p}<$ 0,05 , ini berarti bahwa ada pengaruh antara faktor organisasi dengan self efficacy terhadap penilaian status akreditasi puskesmas.

Hasil uji kekuatan hubungan dengan uji Phi Cramer diperoleh sebesar $\varphi$ 0,133. Karena nilai $\varphi$ berada pada $0,0-0,2$ ini berarti pengaruh sangat lemah dan memberikan kontribusi 13,3 \% terhadap penilaian status akreditasi puskesmas.

Pengaruh faktor Tim Peningkatan Mutu dengan self-efficacy antara Puskesmas yang terakreditasi Dasar-Madya dengan Puskesmas yang terakreditasi UtamaParipurna tahun 2016-2019
Pengaruh faktor Tim Peningkatan Mutu dengan self-efficacy antara puskesmas yang terakreditasi dasar-madya dengan puskesmas yang terakreditasi utamaparipurna tahun 2016-2019 pada Tabel 2 menunjukkan bahwa dari 82 responden dengan faktor tim peningkatan mutu yang Kurang terdapat 27 responden dengan akreditasi utama-paripurna sebesar $32.9 \%$ dan dari 240 responden dengan faktor tim peningkatan mutu yang Cukup, sebanyak 134 responden dengan penilaian akreditasi utama-paripurna atau sebesar $55.8 \%$.

Hasil uji chi square diperoleh nilai $\mathrm{X}^{2}$

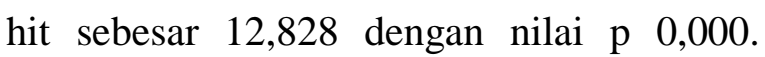
Karena nilai $\mathrm{X}^{2}$ hit > dari 3,841 dan nilai $\mathrm{p}<$ 0,05 , ini berarti bahwa ada pengaruh antara faktor tim peningkatan mutu dengan self efficacy terhadap penilaian status akreditasi Puskesmas.

Hasil uji kekuatan hubungan dengan uji Phi Cramer diperoleh sebesar $\varphi$ 0,200. Karena nilai $\varphi$ berada pada rentang nilai 0,20-0,40 ini berarti pengaruh lemah dan memberikan kontribusi 20,0 \% terhadap penilaian status akreditasi puskesmas.

\section{Pengaruh Self-Efficacy antara Puskesmas} yang terakreditasi Dasar-Madya dengan Puskesmas yang terakreditasi UtamaParipurna tahun 2016-2019

Pengaruh faktor Self-Efficacy antara puskesmas yang terakreditasi dasar-madya dengan puskesmas yang terakreditasi utamaparipurna tahun 2016-2019 pada Tabel 2 menunjukkan bahwa dari 94 Puskesmas dengan faktor Self-Efficacy yang Kurang terdapat 36 Puskesmas dengan akreditasi utama-paripurna atau sebesar 38.3\% dan dari 228 puskesmas dengan faktor Self-Efficacy 
yang Cukup, terdapat 125 Puskesmas dengan penilaian akreditasi utama-paripurna atau sebesar $54.8 \%$.

Hasil uji chi square diperoleh nilai $\mathrm{X}^{2}$

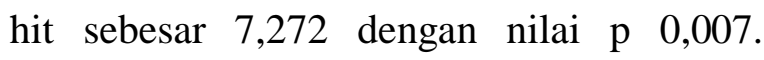
Karena nilai $X^{2}$ hit > dari 3,841 dan nilai $p<$ 0,05 , ini berarti bahwa ada pengaruh antara faktor efikasi diri terhadap penilaian status akreditasi Puskesmas.

Hasil uji kekuatan hubungan dengan uji Phi Cramer diperoleh sebesar $\varphi 0,150$. Karena nilai $\varphi$ berada pada $0,0-0,2$ ini berarti pengaruh sangatt lemah dan memberikan kontribusi $15,0 \%$ terhadap penilaian status akreditasi puskesmas.

\section{Analisis Multivariat}

Variabel yang dimasukkan ke dalam analisis multivariat adalah variabel yang bermakna secara statistik (nilai $\mathrm{p}<0,05$ ). Berdasarkan model akhir regresi logistik terlihat bahwa variabel yang berpengaruh dengan penilaian status akreditasi Puskesmas adalah kepemimpinan, organisasi, tim peningkatan mutu, dan self-efficacy. Analisis multivariat penilaian status akreditasi dapat dilihat pada tabel berikut ini :

Tabel 3. Analisis Multivariat Terhadap Penilaian Status Akreditasi Puskesmas Kota Makassar tahun 2016-2019

\begin{tabular}{|c|c|c|c|c|c|c|c|c|}
\hline \multirow[t]{2}{*}{ Variabel } & \multirow[t]{2}{*}{ B } & \multirow[t]{2}{*}{ S.E. } & \multirow[t]{2}{*}{ Wald } & \multirow[t]{2}{*}{ df } & \multirow[t]{2}{*}{ Sig. } & \multirow[t]{2}{*}{$\operatorname{Exp}(\mathbf{B})$} & \multicolumn{2}{|c|}{$\begin{array}{l}\text { 95\% C.I.for } \\
\text { EXP(B) }\end{array}$} \\
\hline & & & & & & & Lower & Upper \\
\hline Kepemimpinan & -2.333 & .987 & 5.586 & 1 & .018 & .097 & .014 & .671 \\
\hline Organisasi & 1.193 & .659 & 3.281 & 1 & .070 & 3.297 & .907 & 11.991 \\
\hline $\begin{array}{l}\text { Tim Peningkatan } \\
\text { Mutu }\end{array}$ & -.152 & .771 & .039 & 1 & .843 & .859 & .189 & 3.891 \\
\hline Efikasi Diri & .365 & .488 & .561 & 1 & .454 & 1.441 & .554 & 3.748 \\
\hline Constant & 1.097 & .373 & 8.632 & 1 & .003 & 2.995 & & \\
\hline
\end{tabular}

Sumber : data primer, 2020

Tabel 3 menunjukkan bahwa dari hasil uji regresi logistik dimana dari keempat variabel independen, variabel organisasi memiliki nilai $\mathrm{B}$ tertinggi berarti bahwa variabel organisasi merupakan variabel yang paling berpengaruh dibandingkan ketiga variabel yang lain. Dan variable organisasi berpengaruh 1,193 kali terhadap penilaian status akreditasi di Puskesmas Kota Makassar. Nilai B variable kepemimpinan -
2,333 dan variable tim peningkatan mutu -0 , 152 menjelaskan bahwa walaupun variable kepemimpinan signifikan, variable ini tidak terlalu bermakna kepada penilaian akreditasi puskesmas.

Faktor organisasi yang melibatkan kerja sama tim didalam puskesmas lebih berperan besar dibandingkan variable kepemimpinan, tim peningkatan mutu dan efikasi diri. 


\section{PEMBAHASAN}

Hubungan Variabel kepemimpinan terhadap Penilaian Status Akreditasi Puskesmas Kota Makassar tahun 2016-2019

Hasil penelitian menunjukkan dari 244 responden dengan variabel kepemimpinan yang Cukup, sebanyak 107 responden dengan penilaian akreditasi puskesmas dasar-madya atau sebesar $43,9 \%$, sedangkan puskesmas dengan penilaian akreditasi utama-paripurna sebanyak 137 responden atau sebesar $56,1 \%$.

Hasil Uji statistik menunjukkan bahwa ada pengaruh antara variable kepemimpinan dengan penilaian status akreditasi puskesmas, yang berarti bahwa mayoritas tenaga kesehatan di 46 Puskesmas yang menjadi tempat penelitian beranggapan bahwa kepemimpinan yang sudah diterapkan di tempat kerja berada pada kategori Cukup.

Hal ini sejalan dengan penelitian penelitian terdahulu bahwa peran kepemimpinan yang baik dari kepala puskesmas berhubungan dengan motivasi kerja petugas kesehatan di Puskesmas Kota Yogyakarta. Mayoritas responden yang menjawab kepemimpinan yang Cukup, memiliki motivasi kerja tinggi, yang mana motivasi ini terdiri dari motivasi intrinsik dan ekstrinsik. Tenaga kesehatan memiliki hubungan yang harmonis sesama rekan kerja, lingkungan kerja yang nyaman, serta memiliki pemimpin yang dapat memberikan bimbingan dan dorongan untuk bekerja lebih baik lagi. Pimpinan disini harus dapat memperhatikan motivasi kerja karyawan karena motivasi berdampak terhadap kinerja karyawan.Apabila kinerja karyawan ini meningkat maka akan berpengaruh pada pencapaian tujuan organisasi. Hal ini didukung oleh penelitian Heni Rusmitasari (2020) yang menyatakan bahwa ada hubungan antara kepemimpinan dengan motivasi kerja tenaga kesehatan di Puskesmas Kota Yogyakarta dimana gaya kepemimpinan akan menjadi salah satu faktor yang penting untuk menjaga dan meningkatkan motivasi kerja (19).

Hubungan Variabel Organisasi terhadap Penilaian Status Akreditasi Puskesmas Kota Makassar tahun 2016-2019

Hasil penelitian menunjukkan dari 235 responden dengan variabel Organisasi yang Cukup, sebanyak 108 responden dengan penilaian akreditasi puskesmas dasar-madya atau sebesar $46,0 \%$, sedangkan puskesmas dengan penilaian akreditasi utama-paripurna sebanyak 127 responden atau sebesar $54,0 \%$.

Hasil Uji statistik menunjukkan bahwa ada pengaruh antara variabel organisasi dengan penilaian status akreditasi puskesmas, yang berarti bahwa mayoritas responden menilai organisasi di tempat kerjanya dalam kategori cukup. sehingga mampu mewujudkan tujuan puskesmas dalam memberikan pelayanan yang berrkualitas kepada masyarakat, yang mempengaruhi proses penilaian akreditasi Puskesmas.

Pelaksanaan akreditasi membawa banyak perubahan di puskesmas. Perubahan 
organisasi bukanlah proses yang mudah karena anggota organisasi sudah terbiasa dengan kenyamanan dan sistem kerja turun temurun. Proses perubahan dapat membawa dampak psikologis dan emosi dri tim yang terlibat yang akan mempengaruhi perubahan organisasi. Perubahan organisasi dapat dipengaruhi oleh banyak faktor baik internal maupun eksternal. Elemen internal organisasi yang berpengaruh diantaranya manajemen dan budaya organisasi (20).

Hubungan Variabel Tim Peningkatan Mutu terhadap Penilaian Status Akreditasi Puskesmas Kota Makassar tahun 2016-2019

Hasil penelitian menunjukkan dari 240 responden dengan variabel Tim Peningkatan Mutu yang Cukup, sebanyak 106 responden dengan penilaian akreditasi puskesmas dasar-madya atau sebesar 44,2\%, sedangkan puskesmas dengan penilaian akreditasi utama-paripurna sebanyak 134 responden atau sebesar 55,8\%.

Hasil Uji statistik menunjukkan bahwa ada pengaruh antara variabel Tim Peningkatan Mutu dengan penilaian status akreditasi puskesmas, yang berarti bahwa mayoritas tenaga kesehatan menilai tim peningkatan mutu di tempat kerjanya berada dalam kategori cukup. Hal ini sesuai dengan tujuan utama terakreditasinya sebuah puskesmas diharapkan terjadinya peningkatan kinerja melalui perbaikan secara berkelanjutan terhadap sistem manajemen mutu, sistem penyelenggaraan pelayanan program, sistem manajemen pelayanan serta dapat meningkatkan penerapan manajemen risiko pada pasien.
Hubungan Variabel Efikasi Diri terhadap Penilaian Status Akreditasi Puskesmas Kota Makassar tahun 2016-2019

Efikasi Diri adalah penilaian diri, apakah dapat melakukan tindakan baik atau buruk, tepat atau salah, bisa atau tidak bisa, mengerjakan sesuatu sesuai dengan yang dipersyaratkan.

Hasil penelitian menunjukkan dari 103 responden dengan variable efikasi diri yang cukup, sebanyak 106 responden dengan penilaian akreditasi puskesmas dasar-madya atau sebesar 45,2\%, sedangkan puskesmas dengan penilaian akreditasi utama-paripurna sebanyak 125 responden atau sebesar 54,8\%.

Hasil Uji statistik menunjukkan bahwa ada pengaruh antara variable SelfEfficacy dengan penilaian status akreditasi puskesmas, yang berarti bahwa mayoritas tenaga kesehatan menilai Self-Efficacy di tempat kerjanya berada dalam kategori cukup, beraspek pada pelayanan yang diberikan kepada masyarakat dan berpengaruh pada penilaian akreditasi di puskesmas tempatnya bekerja.

Standar kualitas yang tertulis dalam pedoman akreditasi menetapkan bahwa audit kualitas baik internal maupun eksternal adalah kewajiban yang harus dilakukan secara rutin. Aturan ini telah berhasil merombak berbagai kebiasaan dan pola tata kelola program dari cara konvensional menjadi lebih profesional dan akuntabel. Namun sayangnya tidak semua petugas kesehatan di puskesmas siap untuk berubah. Dalam sebuah survei yang dilakukan di salah satu puskesmas di Surabaya, masih ada 
$4,9 \%$ staf yang tidak mendukung proses akreditasi, dan 9,8\% staf merasa acuh tak acuh. Sikap para petugas ini tentu akan mempengaruhi kesiapan puskesmas untuk berubah.

Hal ini sejalan dengan penelitian Ratna Dwi tahun 2019 yang dilakukan di puskesmas di Surabaya, bahwa yang memiliki hubungan signifikan dengan implementasi perubahan adalah efikasi Adanya komitmen yang tinggi membuat staf Puskesmas bersedia untuk bekerja lebih giat, tetapi jika tidak dibarengi dengan efikasi maka hasil yang diperoleh tidak akan maksimal. Komitmen tersebut memang membuat staf puskesmas memiliki niat kuat untuk melakukan pelayanan kesehatan sesuai dengan standar kualitas yang seharusnya, tetapi jika ini tidak didukung oleh keyakinan bahwa mereka dapat menerapkan standar kualitas dengan baik, yang akan terjadi adalah penurunan motivasi (21).

\section{KESIMPULAN}

1. Variabel kepemimpinan berpengaruh terhadap penilaian status akreditasi Puskesmas tahun 2016-2019.

2. Variabel organisasi berpengaruh terhadap penilaian status akreditasi Puskesmas tahun 2016-2019.

3. Variabel Tim Peningkatan Mutu berpengaruh terhadap penilaian status akreditasi Puskesmas tahun 2016-2019

4. Variabel Self-Efficacy berpengaruh terhadap penilaian status akreditasi Puskesmas tahun 2016-2019.
5. Variabel Organisasi merupakan variabel yang paling bermakna berdasarkan hasil Uji Statistik.

\section{DAFTAR PUSTAKA}

1. WHO. Monitoring the building blocks of health systems: a handbook of indicators and their measurement strategies. Geneva: World Health Organization; 2010.

2. Kementerian Kesehatan. Peraturan Menteri Kesehatan tentang Pusat Kesehatan Masyarakat. JakartaNomor 43 Tahun 2019.

3. Saenong MT. Mutu Pelayanan Kesehatan Puskesmas. Makassar: Nas Media Pustaka; 2019.

4. Kementerian Kesehatan. Rencana Aksi Nasional Direktorat Mutu dan Akreditasi Pelayanan Kesehatan Tahun 2016 - 2019. Jakarta: 2016; 2016.

5. Kuspijani, Sudarso I. Pengukuran Kinerja Fakultas Teknik Universitas Bhayangkara Surabaya (UBHARA) Surabaya dengan Menggunakan Kriteria Malcolm Baldrige. Institut Teknologi Sepuluh Nopember (ITS - Surabaya), Surabaya. 2010.

6. Brown MG. Baldrige Award Winning Quality: How to Interpret the Baldrige Criteria for Performance Excellence. 17 ed. New York: CRC Press; 2008.

7. Kaplan HC, Provost LP, Froehle CM, Margolis PA. The Model for Understanding Success in Quality (MUSIQ): building a theory of context in healthcare quality improvement. BMJ Qual Saf. 2012;21(1):13-20.

8. Manurung S, Hidayat R, Patras YE, Fatmasari R. Peningkatan Efektivitas Kerja melalui Perbaikan Pelatihan, Penjaminan Mutu, Kompetensi Akademik dan Efikasi Diri dalam Organisasi Pendidikan. Manageria: 
Jurnal Manajemen Pendidikan Islam. 2018; Volume 3, Nomor 1, Mei 2018/1439

9. Tahir M, Amiruddin R, Palutturi S, Rivai F, Saleh LM, B OW. Quality Evaluation of Health Service at Community Health Centers : Through Accreditation Surveys in Indonesia Indian Journal of Public Health Research and Development. 2020;11.

10. Kementerian Kesehatan. Peraturan Menteri Kesehatan tentang Akreditasi Puskesmas, Klinik Pratama, Tempat Praktik Mandiri Dokter, dan Tempat Praktik Mandiri Dokter Gigi. JakartaNomor 46 Tahun 2015.

11. Yewen MR, Korompis GEC, Kolibu FK. Hubungan Antara Status Akreditasi Puskesmas dengan tingkat kepuasan Pasien di Kota Sorong Provinsi Papua Barat. Jurnal KESMAS. 2018; vol. 7 no. 5.

12. Dinas Kesehatan Kota Makassar d, ISPEI. Laporan Hasil Survei Kepuasan Masyarakat Terhadap Pelayanan Puskesmas dan RSUD Kota Makassar. Makassar: 2019.

13. Haj-Ali W, Karroum LB, Natafgi N, Kassak K. Exploring the relationship between accreditation and patient satisfaction-the case of selected Lebanese hospitals. International Journal Of Health Policy Management. 2014;3(6):341.

14. Strumpf E, Levesque JF, Coyle N, Hutchison B, Barnes M, Wedel RJ. Innovative and diverse strategies toward primary health care reform: lessons learned from the Canadian experience. $\mathrm{J}$ Am Board Fam Med. 2012;25 Suppl 1(Suppl 1):S27-33.

15. Heuer AJ. Hospital accreditation and patient satisfaction: testing the relationship. J Healthc Qual. 2004;26(1):46-51.

16. Ulumiyah NH. Meningkatkan Mutu Pelayanan Kesehatan Dengan Penerapan
Upaya Keselamatan Pasien Di Puskesmas Jurnal Administrasi Kesehatan Indonesia. 2018; Volume 6 No 2 July-December 2018.

17. Susanto E. Pengaruh Efikasi Diri, Disiplin Kerja Dan Pelayanan Terhadap Kinerja Pegawai Puskesmas Di Kecamatan Lempuing Jaya Kabupaten Ogan Komering Ilir. Jurnal Ilmiah FEUMM. 2018;Vol. 12 (2018) No. 2 ISSN Cetak 1978-6573.

18. Sugiyono PD. Metode Penelitian Kuantitatif dan Kualitatif dan R\&D. Bandung (ID): Alfabeta; 2008.

19. Heni Rusmitasari, Mudayana AA. Kepemimpinan dan Motivasi Kerja Tenaga Kesehatan di Puskesmas Kota Yogyakarta. JURNAL KESEHATAN MASYARAKAT INDONESIA. 2020; Volume 15, Nomor 1.

20. Ratna Dwi Wulandari, Ilham Akhsanu Ridho, S. Supriyanto, M. Bagus Qomaruddin, Nyoman Anita Damayanti, Agung Dwi Laksono, et al. Pengaruh Pelaksanaan Akreditasi Puskesmas terhadap Kepuasan Pasien Media Kesehatan Masyarakat Indonesia (The Indonesian Journal Of Public Health). 2019; Vol. 15 No. 3.

21. Ratna Dwi Wulandari, S. Supriyanto, M. Bagus Qomaruddin, Nyoman Anita Damayanti, Laksono AD. Change Commitment and Change Efficacy of Public Health Center in Indonesia in Implementing Efforts to Improve the Quality of Health Services. Indian Journal of Public Health Research and Development. 2019. 